\title{
(DE)FORMAÇÃO DA INDIVIDUALIDADE E (IN) DISPOSIÇÃO PARA A VIOLÊNCIA: PRESSUPOSTOS SUBJETIVOS E OBJETIVOS ${ }^{1}$
}

\author{
Luís CÉSAR SOUZA \\ Universidade Federal de Goiás (UFG), Regional Jataí, Goiás, Brasil
}

\begin{abstract}
Resumo: As reflexões aqui desenvolvidas buscam analisar como a constituição do Eu a partir da relação entre indivíduo e cultura, portanto considerando aspectos subjetivos e objetivos, pode resultar em renúncia ou em disposição ao comportamento violento. Por meio de pressupostos da teoria crítica frankfurtiana, especialmente em H. Marcuse, T.W. Adorno e M. Horkheimer, partese da análise freudiana sobre a importância da autoridade do "pai" no seio da família nuclear para a constituição do Eu, porém, procurase atualizar essa discussão e indagar se as condições objetivas de existência na atualidade, na era das sociedades administradas e tecnológicas, não estariam levando à (de)formação de uma individualidade mais disponível para aderir à violência e praticá-la.

Palavras-chave: Formação. Individualidade. Violência. Sociedade administrada e tecnológica.
\end{abstract}

INTRODUÇãO

A disposição de indivíduos em aderir a comportamentos violentos e praticá-los não é, seguramente, uma situação com origem nas sociedades modernas e contemporâneas. A rigor, o histórico de episódios violentos remonta à própria constituição da civilização. Contudo, nos últimos anos, parece haver um evidente aumento de comportamentos violentos, em âmbito local ou universal, por ações individuais ou coletivas. É verdade 
que esse aumento pode estar relacionado à universalização dos meios de comunicação que, por meio da televisão, de computadores ou de telefones, possibilitou o acesso a notícias de todas as partes do mundo, aumentando também o contato com ocorrências de violência. Como exemplo, poder-se-ia citar a escalada da ideologia fascista, ilustrada, em âmbito internacional, pelo nacionalismo ultraconservador do presidente dos Estados Unidos, Donald Trump, e, no cenário nacional, pelas incontáveis declarações de indivíduos que não se envergonham de desejar a eliminação do outro diante de conflitos políticos, econômicos e culturais em que, nós, brasileiros, nos encontramos - declarações estas amplificadas diariamente pelas chamadas redes sociais. Mesmo assim, para além do fato de que vivemos uma era em que a violência parece aumentar exponencialmente, é indiscutível que a desafiadora pergunta feita por estudiosos e pesquisadores sobre o assunto, em diferentes momentos da história da humanidade, permanece absolutamente atual, qual seja: que aspectos concorrem para que o indivíduo renuncie ou se apresente disposto ao comportamento violento? As possíveis respostas a essa problemática expressam diferentes concepções a respeito do homem, da sociedade, da educação. Nos limites deste texto, optou-se por discutir pressupostos subjetivos e objetivos que se entrecruzam na constituição do Eu e que podem resultar na formação ou na deformação do indivíduo. Para realizar essa tarefa, buscou-se por fundamentos na teoria crítica da sociedade para compreender como as fragilidades na constituição do Eu nas sociedades administradas, e atualmente tecnológicas, podem implicar a formação de um tipo de individualidade vulnerável a aderir a comportamentos violentos e praticá-los.

Por meio desses fundamentos, pretende-se evitar uma interpretação determinista, que reduz a violência a aspectos socioeconômicos, como também uma perspectiva subjetivista que limita a análise a estruturas cognitivas. Se a violência tem uma causa objetiva, é necessário compreender o sentido que o indivíduo atribui a ela. Se, em decorrência do modo como se produz a vida em sociedade, a violência pode ser ampliada ou minimizada, é indispensável considerar os aspectos subjetivos que tornam as pessoas disponíveis a ela.

\section{DA AGRESSIVIDADE À VIOLÊNCIA E À CULTURA}

A compreensão da violência, de um modo geral, exige o entendimento sobre a relação entre o indivíduo e a cultura. Na perspectiva freudiana, a cultura se desenvolve a partir do conflito entre as exigências dos impulsos agressivos e os limites impostos pela realidade a eles. ${ }^{2}$ À medida que, 
historicamente, esses impulsos foram sendo "controlados" pela civilização, a cultura se desenvolveu e se ampliaram os mecanismos necessários ao seu controle.

A orientação bíblica "não matarás" ilustra os limites que a civilização precisou impor aos impulsos agressivos que, filogenética e ontogeneticamente, são constitutivos do indivíduo. Por isso, "a existência desse pendor à agressão, que podemos sentir em nós mesmos e justificadamente pressupor nos demais, é o fator que perturba nossa relação com o próximo e obriga a civilização a seus grandes dispêndios" (FREUD, 2011, p. 57). Pela agressividade primária do ser humano pode-se compreender o argumento freudiano de que a sociedade, independentemente do modo de sua organização, "é permanentemente ameaçada de desintegração", ainda que seja precisamente a luta contra essa desintegração que justifica a cultura. Se bem compreendida, essa "ameaça" contraria o argumento de que o indivíduo é naturalmente bom, uma vez que "o ser humano não é uma criatura branda, ávida de amor, que no máximo pode se defender, quando atacado, mas sim que ele deve incluir, entre seus dotes instintuais, também um forte quinhão de agressividade" (FREUD, 2011, p. 57). Para o autor, mesmo se a humanidade chegasse a um modelo de organização em que as relações sociais fossem harmônicas, a propriedade privada abolida e o trabalho realizado sob os princípios da necessidade e da capacidade de cada um, ainda assim, seria difícil superar o conflito constitutivo do indivíduo na relação com a cultura e as consequências que resultam desse processo.

Com o desenvolvimento das normas sociais, as relações humanas podem se tornar mais harmônicas, o que permite afirmar que "a cultura é o termômetro que mede os limites toleráveis de agressividade para o que se entende por aceitação social" (ZANOLLA, 2010). No entanto, as limitações impostas pela cultura podem ser absorvidas ou não pelo indivíduo e amenizar ou não os impulsos agressivos, e a maior ou menor absorção delas depende do modo como são experienciadas e internalizadas. Assim, um aspecto importante que move o indivíduo é a realização de seus impulsos primários e suas vontades, o que Freud (2011) caracteriza como a busca pela felicidade no sentido de experiências prazerosas e ausência de dor e desprazer. Contudo, em nome da convivência comum, somos "obrigados" a diminuir a intensidade dessa busca, pois, se todos agissem sem restrição para satisfazê-la, não seria possível a civilização. Isso implica dizer que a felicidade plena é impossível e o que ocorre são momentos de bem-estar:

aquilo a que chamamos felicidade, no sentido mais estrito, vem da satisfação repentina de necessidades altamente represadas, e por sua natureza é 
possível apenas como fenômeno episódico. [...] Logo, nossas possibilidades de felicidade são restringidas por nossa constituição. É bem menos difícil experimentar a infelicidade (FREUD, 2011, p. 20).

Isso representa um dilema na relação do indivíduo com a cultura porque, por mais que se busque prazer e satisfação, eles não se realizam por completo. E apesar das restrições impostas pela cultura, o que se apresenta nessa relação é uma ambivalência que justifica o desenvolvimento histórico de ambos: "o programa de ser feliz, que nos é imposto pelo princípio do prazer, é irrealizável, mas não nos é permitido - ou melhor, não somos capazes de - abandonar os esforços para de alguma maneira tornar menos distante a sua realização" (FREUD, 2011, p. 28). Dessa tensão entre possibilidade e impossibilidade mediante o conflito entre as reivindicações dos impulsos primários e a censura das normas sociais, isto é, da cultura internalizada, o Eu se constitui. Nesse processo, emergem desafios a serem compreendidos, como: de que meio se vale a cultura para inibir, tornar inofensiva, talvez eliminar a agressividade que a defronta? Ou ainda: o que sucede no indivíduo que ameniza e torna inofensivo o seu gosto em agredir? Um passo na busca por respostas a essas questões é compreender como os impulsos primários são exteriorizados na cultura e dela retornam ao indivíduo:

a agressividade é introjetada, internalizada, mas é propriamente mandada de volta para o lugar de onde veio, ou seja, é dirigida contra o próprio Eu. Lá é acolhida por uma parte do Eu que se contrapõe ao resto como Super-eu, e que, como "consciência", dispõe-se a exercer contra o Eu a mesma severa agressividade que o Eu gostaria de satisfazer em outros indivíduos. À tensão entre o rigoroso Super-eu e o Eu a ele submetido chamamos consciência de culpa; ela se manifesta como necessidade de punição. A civilização controla então o perigoso prazer em agredir que tem o indivíduo, ao enfraquecê-lo, desarmá-lo e fazer com que seja vigiado por uma instância no seu interior, como por uma guarnição numa cidade conquistada (FREUD, 2011, p. 69).

Assim, dois conceitos são fundamentais para entender os impulsos à agressividade: o superego e o sentimento de culpa amplificado por ele. ${ }^{3} \mathrm{O}$ superego refere-se à censura imposta ao Eu a fim de evitar o cometimento de atitudes "ilícitas"; é a consciência moral internalizada pelo Eu devido às repressões advindas da regulação social. Por sentimento de culpa, entende-se "a percepção que tem o Eu de ser vigiado, assim, a apreciação da tensão entre os seus esforços e as exigências do super-eu, e o medo ante essa instância crítica" (FREUD, 2011, p. 83). Nessa dinâmica, os impulsos agressivos são direcionados à cultura, no entanto, as regulamentações sociais fazem com que estes retornem ao indivíduo devido à impossibilidade de realizá-los. Esse 
retorno leva o Eu a perceber essa impossibilidade e desenvolver a consciência de normas culturais - que significa o superego internalizado. Já o sentimento de culpa se encarrega de lembrar ao indivíduo que os impulsos agressivos não devem se materializar, e isso ocorre de duas maneiras: devido às experiências que a realidade externa reprimiu, o que pode gerar arrependimento pelo ato ilícito consumado; posteriormente, por meio da censura do superego, o sentimento de culpa ocorre mesmo antes de ser praticado o ato. Dessa dinâmica, emerge a consciência:

no início a consciência (mais corretamente: o medo que depois se torna consciência) é a causa da renúncia instintual, mas depois se inverte a relação. Toda renúncia instintual se torna uma fonte dinâmica da consciência, toda nova renúncia aumenta o rigor e a intolerância desta, e, se pudéssemos harmonizar isso melhor com o que sabemos da história da origem da consciência, seríamos tentados a defender a tese paradoxal de que a consciência é o resultado da renúncia instintual, ou de que esta (a nós imposta do exterior) cria a consciência, que então exige mais renúncia instintual (FREUD, 2011, p. 75).

Na dinâmica de constituição do Eu, é importante distinguir a agressividade da violência. Na verdade, é fundamental compreender que a agressividade pode ser amenizada e canalizada para a cultura ou manifestarse como violência, pois, como assinala Zanolla (2010, p. 118), "a agressividade extrapola o sentido da violência. A agressividade diz respeito a um elemento primário, inerente ao ser humano e compõe a energia libidinal. ${ }^{4}$ [Ela] rege a necessidade de satisfação imediata (o princípio do prazer)". Já a violência resulta de uma perturbação no processo de constituição do Eu, ou seja, remonta ao conflito entre os impulsos primários e a censura imposta pela cultura. Sob esse entendimento a autora argumenta que

a violência é uma contingência da energia libidinal que retorna aos instintos agressivos sob a forma de razão. Para que o sujeito possa sublimar sua agressividade deverá reprimir seus instintos mais agressivos de satisfação imediata e, com isso, passar pelo teste de realidade, elaborar essa energia como possibilidade de ser aceito socialmente e adquirir cultura (princípio de realidade) (ZANOLLA, 2010, p. 119).

Desse modo, para a compreensão da violência que se manifesta socialmente, a sublimação também revela-se uma ferramenta importante, pois, a partir dela, é possível inferir o que acontece com os impulsos agressivos devolvidos ao Eu pela realidade externa, isto é, na medida em que o Eu se constitui, a energia que a ele retorna pode ser conduzida para atividades socialmente valorizadas ou não. De acordo com Freud (2011, p. 42), esse 
processo foi fundamental no desenvolvimento da civilização, uma vez que a "sublimação do instinto é um traço bastante saliente da evolução cultural, ela torna possível que atividades psíquicas mais elevadas, científicas, artísticas, ideológicas, tenham papel tão significativo na vida civilizada". Porém, o autor adverte que este não é o destino de toda energia que resulta da repressão aos instintos, afinal, não é a única forma de recompensar o Eu. Isso significa que a não sublimação pode resultar em perturbações associadas à (de)formação da individualidade e, como consequência, desencadear comportamentos violentos.

Essa dinâmica deve ser compreendida dentro de um movimento dialético, e Zanolla (2010, p. 118, grifo meu) o reconhece ao afirmar que "o preço da cultura ou da educação é mais que castração ou interdição, é elaboração e renúncia". Ainda que as restrições impostas pela cultura configurem castrações aos impulsos primários, elas não devem ser consideradas como "fins" na relação entre indivíduo e cultura, e sim como "meios". Os fins devem objetivar a busca pelo que de mais elaborado existe na cultura, por isso, o desafio posto é fazer com que a superação da agressividade resulte em elaboração e renúncia, e não em violência. Por sua vez, a violência deve ser compreendida como uma consequência que resulta da maior ou da menor capacidade do indivíduo em elaborar os impulsos agressivos e renunciar a eles, o que inevitavelmente remete ao processo de sua formação. ${ }^{5}$

Sobre a individualidade constituída na relação com o outro e com a cultura, é preciso registrar que ela não se forma mediante um processo estático em que se verificam início e fim definidos, mas decorre do modo como as relações são absorvidas e ressignificadas. E embora o indivíduo esteja em permanente formação ao longo da vida, devem ser buscados na infância os elementos primeiros de sua constituição, especialmente aqueles que se estabelecem no âmbito familiar.

A partir da teoria freudiana, Costa (2003) recorda que a referência à autoridade na primeira infância, representada pela figura do "pai", é fundamental para a formação de um Eu capaz de enfrentar as contradições presentes nas relações com o outro e com a sociedade. A autoridade do pai possibilita experiências afetivas que podem resultar em satisfação, como também em frustração; por isso, ela não se limita à imagem do chefe de família apenas, e sim à representação de uma autoridade que pode levar a criança à renúncia do amor primevo e possibilitar sua inserção na cultura. Por outra via, a impotência dessa autoridade pode representar a ausência de lei e ordem necessárias à organização do "caos imaginário" que perpassa a infância. Uma consequência dessa ausência é que o indivíduo passa a cobrar da sociedade 
aquilo que deveria ser propiciado por uma pessoa, isto é, as funções atribuídas ao "universo do privado" (família) passam a ser cobradas do "universo do público" (sociedade). Esta é uma situação paradoxal porque, ainda que não se tenha consciência dela, o indivíduo espera que a sociedade supra uma função que ela própria atribuiu à família previamente (COSTA, 2003).

Sobre a relação entre família e sociedade, Horkheimer (1990, p. 214) reconhece que, "assim como a realidade se reflete no meio deste círculo [a família], a criança que cresce dentro dele sofre sua influência". Nesse movimento, a autoridade familiar promove uma adaptação à ordem social vigente, pois "a criança, ao respeitar na força paterna uma relação moral e, assim, aprender a amar no seu coração aquilo que ela, com a sua inteligência, constata como existente, aprende a primeira lição na relação burguesa de autoridade" (HORKHEIMER, 1990, p. 216). Nesse sentido, as relações afetivas que se desenvolvem no âmbito da família desempenham a função de preparar o indivíduo para a inserção social. Contudo, o autor ressalta que esse processo não é tão linear quanto parece, mas sim dialético.

Se, por um lado, a submissão da autoridade familiar às normas da sociedade burguesa reforça a formação de uma individualidade adaptada em que os indivíduos, por exemplo, "não questionam a estrutura do sistema econômico e social, mas o aceitam como natural e eterno e deixam ainda que seu descontentamento e rebelião se transformem em forças executantes da ordem vigente" (HORKHEIMER, 1990, p. 221), por outro lado, na medida em que o círculo familiar experimenta os sofrimentos desta realidade, "que sob o signo da autoridade oprimem a existência, pode nascer uma nova comunidade de casais e filhos, que por certo não está fechada, à moda burguesa, contra outras famílias do mesmo tipo ou contra os indivíduos do mesmo grupo" (HORKHEIMER, 1990, p. 233). Como consequência, tanto a tendência adaptativa como a possibilidade de autonomia e resistência são aspectos que integram dialeticamente a formação inicial do Eu na tensão com a autoridade presente na família nuclear. Como ressalta Zanolla (2010, p. 121), "embora contraditória, a instituição familiar possibilita à criança elaborar valores e referências, e sua destituição leva à recaída ao estado de ignorância e de agressividade humanas". Por isso, se são negligenciadas situações que possibilitariam ao indivíduo experimentar o conflito com o outro e com a cultura, pode-se abrir o caminho para a formação de um tipo de individualidade mais tolerante à violência.

Como o comportamento violento pode derivar de uma perturbação na formação do Eu, de sua individualidade, cabe então perguntar: o que caracteriza a violência? No entendimento de Costa (2003), em 
sentido moderno a violência está associada ao menos a dois sentidos: ao constrangimento pelo uso de força física ou de intimidação moral contra outrem e a questões relativas à infração da lei e da justiça pelo abuso de poder. Em ambos os sentidos, a violência pressupõe domínio e coerção e se materializa nas relações sociais. Mas, então, todo ato de coerção deve ser considerado violento? A violência se instaura devido ao estímulo e à quantidade de força física ou moral? Para o autor, as respostas a essas questões seriam negativas - embora não se deve desprezar que a força empregada no ato pode ampliá-la. Sendo assim, qual o parâmetro para verificar a ocorrência ou não de violência?

$\mathrm{Na}$ formulação de uma resposta a essas questões, Costa (2003) assinala que não é sempre que a coerção está associada à violência e explica que o fato de um adulto recorrer a processos coercitivos a fim de promover a internalização da cultura pelos filhos e pelas crianças não pode ser considerado, sem mais, como ato violento. Seria preciso distinguir outros aspectos presentes no processo coercitivo, pois

existe, como sempre existiu, pais que levam os filhos a abandonarem certas atitudes alegando mágoa, vergonha, tristeza ou decepção que tais atitudes Ihes causam. A palmada e o recurso à culpa talvez sejam hoje em dia mais suaves e menos difundidos do que foram tempos atrás. Entretanto, no passado como no presente crianças educadas neste sistema de normas morais não foram nem são necessariamente crianças violentadas. [...] Durante muito tempo, quem sabe até hoje, muitos pais intimidaram moralmente os filhos em nome do compromisso ético-religioso de honrar pai e mãe, sem que isto revertesse obrigatoriamente em violência (COSTA, 2003, p. 123).

Também sob esse entendimento, em suas conferências radiofônicas no final da década de 1960, em que uma questão abordada foi a violência na primeira infância, Adorno já argumentava que o uso da autoridade "não cega" pelos pais é indispensável na luta contra a barbárie. Reportando-se a situações frequentemente banalizadas, afirma que, "quando os pais 'dão uma palmada' na criança porque ela arranca as asas de uma mosca, trata-se de um momento de autoridade que contribui para a desbarbarização" (ADORNO, 1995, p. 167). Por isso, procedimentos como esses não podem ser concebidos como violência, pois representam "meios" e não "fins", isto é, a intimidação moral e a palmada podem, em diferentes contextos, figurar como recursos necessários para a internalização da cultura e a efetiva realização da educação.

Sendo a coerção, por si só, insuficiente para caracterizar uma ação ou um estímulo como violento, é necessário compreender o significado e o sentido atribuídos pelo sujeito ao estímulo coercitivo. Assim, a violência 
ocorre quando o estímulo é absorvido pelo indivíduo violentado como um ato desnecessário, o que pressupõe "a existência de um uso arbitrário e gratuito da força por parte do mais poderoso contra o mais fraco. Violência é, antes de tudo, abuso de força, abuso de poder" (COSTA, 2003, p. 124, grifo do autor). Ou ainda, na violência

o que domina é o sentimento ou pensamento da gratuidade e do arbítrio. O sujeito violentado é o sujeito que sabe ou virá a saber, sente ou virá a sentir, que foi submetido a uma coerção e a um desprazer absolutamente desnecessários ao crescimento, desenvolvimento e manutenção de seu bem-estar (COSTA, 2003, p. 125).

Desse modo, a ocorrência de violência depende, por um lado, do nível de intensidade do estímulo ou do ato e, por outro, do grau com que ele é absorvido e ressignificado pelo sujeito violentado; e ambos devem ser submetidos ao parâmetro da necessidade ou da gratuidade com que ocorrem. Esse conjunto de fatores deve ser confrontado, ainda, ao critério e à noção de saber se o ato tem como fim a formação verdadeiramente humana do indivíduo. No entanto, se a manifestação da violência depende da constituição do Eu na relação entre indivíduo e cultura, sendo a autoridade no seio da família nuclear decisiva nesse processo, cabe a pergunta: a família nuclear continua a influenciar a formação do Eu na sociedade atual? Ou: que tipo de individualidade se forma no contexto das sociedades administradas e tecnológicas?

(DE)FORMAÇÃO DO INDIVÍDUO NAS SOCIEDADES ADMINISTRADAS E TECNOLÓGICAS

As reflexões a partir dos pressupostos freudianos são fundamentais para compreender aspectos subjetivos que explicam a formação do Eu no conflito com os aspectos objetivos, isto é, a cultura. Mesmo assim, Horkheimer e Adorno (1973) e Marcuse (1998) ressaltam que é preciso considerar o tempo e o espaço em que elas estão situadas: a Europa no período entre as duas guerras mundiais. Sobre esse contexto, como assinala Hobsbawm (1995), cabe lembrar que a primeira metade do século XX foi marcada pelo colapso da civilização ocidental do século anterior e por grandes catástrofes. Uma sociedade em que as forças produtivas não haviam ainda alavancado o desenvolvimento da tecnologia, como ocorreria de modo exponencial após a Segunda Guerra Mundial. Aqui, a relativa distribuição da riqueza nos países de capitalismo avançado - configurando o chamado Welfare State - e o desenvolvimento da ciência e da tecnologia tornaram possível "levar a cada residência, todos os dias, a qualquer hora, mais informação e diversão do que 
dispunham os imperadores em 1914. Ele [o desenvolvimento tecnológico] dava condições às pessoas de se falarem entre si cruzando oceanos e continentes ao toque de alguns botões" (HOBSBAWM, 1995, p. 22). Nesse cenário de intenso desenvolvimento das forças produtivas, cabe perguntar: a constituição do Eu mediante o conflito entre os impulsos agressivos e a cultura permanecem inalterados nessas sociedades? Como se forma a individualidade nessas circunstâncias? O exercício de responder a perguntas como estas, a partir de fundamentos de uma teoria crítica da sociedade, ajuda a entender a violência social e a barbárie que, também hoje, se manifestam de maneiras e em espaços diferentes.

$\mathrm{Na}$ análise sobre a constituição do Eu, Marcuse assinala que, nas sociedades industriais avançadas, a teoria freudiana se tornou obsoleta e indispensável ao mesmo tempo, isto é, os princípios fundamentais daquela teoria

se tornaram obsoletos na medida em que seu objeto, o"indivíduo" enquanto encarnação do id, ego e superego, se tornou obsoleto na realidade social. [...] A verdade da psicanálise nem por isso se enfraquece; pelo contrário, a obsolescência de seu objeto manifesta a que ponto o progresso foi, na realidade, repressão. A psicanálise lança assim nova luz sobre a política da sociedade industrial avançada (MARCUSE, 1998, p. 91).

O frankfurtiano considera que Freud desenvolveu uma teoria crítica - no sentido de desvelar a estrutura psíquica, que não é aparentemente observável, na relação com a cultura - fundamental para entender a sujeição do indivíduo nas sociedades administradas e com o advento da tecnologia. Entretanto, adverte não ser uma atitude teórica adequada simplesmente transportar os princípios da análise freudiana para a análise da sociedade atual sem considerar novas mediações, pois, se a sociedade continua industrial e capitalista, o desenvolvimento econômico e político-ideológico, no contexto da burocracia e da racionalidade tecnológica, determina novos parâmetros que interferem na constituição do Eu e na formação do indivíduo (MARCUSE, 1999).

Uma dessas "novidades" é que, em seu entendimento, na fase atual da sociedade industrial, o clássico conflito que a criança deveria experimentar na família nuclear mediante a autoridade do"pai" deixa de ser predominante, uma vez que tanto a família como o pai deixaram de ser o espaço de primeira socialização e referência. Para Marcuse (1998, p. 94), a situação"em que ego e superego se formavam na luta com o pai como representante paradigmático do princípio de realidade [...] é uma situação histórica: ela deixou de existir com as transformações da sociedade industrial que se produziram no período do 
entreguerras". Certamente que isso não significa que deixaram de existir e de influenciar a constituição do Eu, ou seja, o pai continua a forçar a separação primária da sexualidade da figura da mãe, mas sua autoridade já não é reforçada nem perpetuada por seu posterior poder educativo e econômico como fora antes. Novamente, cabe indagar: o enfraquecimento da autoridade na família nuclear pode levar à formação de um tipo de individualidade mais tolerante à violência? Ou ainda: como essas transformações influenciam o pensamento e o comportamento do indivíduo na sociedade administrada e tecnológica?

Uma resposta a essas questões foi esboçada pelo autor no início da década de 1960 em seu livro A ideologia da sociedade industrial. Um argumento central é que o fato de a sociedade afluente ser permeada pela burocracia nas relações de produção e pela tecnologia como substrato das forças produtivas implicou mudanças no âmbito objetivo que afetaram a estrutura subjetiva. A dissolução do "pai"e da família nuclear sob sua autoridade como agentes de socialização fundamental abriu caminho para a sociedade dirigir diretamente o Eu em formação "através dos mass media, dos agrupamentos escolares e esportivos, dos bandos de jovem etc." (MARCUSE, 1998, p. 94, grifo do autor). Assim, a estrutura psíquica, as obrigações e o comportamento socialmente necessário do indivíduo - filho, criança, as gerações que nascem e se desenvolvem no contexto das sociedades administradas e tecnológicas - deixam de ser apreendidos e internalizados a partir da longa luta com o pai, e o superego passa a agir direta e externamente sobre o Eu antes que este tenha se constituído sob relativa autonomia.

Essas transformações reduzem o "espaço vital" e a autonomia do ego e preparam o terreno para o surgimento das massas. Na estrutura da sociedade, o indivíduo torna-se um objeto administrado, consciente e inconsciente, e obtém liberdade e satisfação em seu papel como um tal objeto: na estrutura psíquica o ego se contrai de tal maneira que já não parece capaz de se manter como um eu distinto do id e do superego. A dinâmica pluridimensional, em virtude da qual o indivíduo alcançava e mantinha seu equilíbrio entre a autonomia e a heteronomia, a liberdade e a repressão, o prazer e a dor, deu lugar a uma dinâmica unidimensional, a uma identificação estática do indivíduo com seus semelhantes e com o princípio de realidade administrado (MARCUSE, 1998, p. 94).

Essa dinâmica unidimensional se constitui e se desenvolve por meio de um aparato burocrático e tecnológico, no plano objetivo, e pela dissolução da possibilidade de formação do indivíduo (relativamente) autônomo, no âmbito subjetivo, o que resulta na constituição de um “Eu enfraquecido". Nesse 
processo, o indivíduo não percebe a repressão que recai sobre si e, por isso, não oferece resistência à sociedade que assim se organiza. ${ }^{6}$ Paradoxalmente, a libertação da autoridade familiar representa mais um inconveniente para o indivíduo do que uma vantagem, pois "o ego, tendo se desenvolvido sem muita luta, aparece como uma entidade fraca, pouco apropriada a tornar-se um eu com os outros e contra eles, a opor uma resistência eficaz às forças que impõem agora o princípio de realidade" (MARCUSE, 1998, p. 98). Em decorrência, a necessária diferenciação da realidade pelo indivíduo é obstruída e se instauram as bases para uma sociedade de massas, afinal, passa a existir uma identificação imediata entre os interesses individuais e os interesses coletivos moldados pela sociedade administrada e tecnológica.

Retomando a discussão freudiana de que no processo de idealização o indivíduo substitui o ideal de ego pelo ideal de grupo, o autor frankfurtiano argumenta que "nessa confusão, o ideal do ego universal impõe-se, unificando os indivíduos em cidadãos de sociedade de massas. [E] O código técnico, o código moral e o da produtividade lucrativa fundem-se num todo efetivo" (MARCUSE, 1998, p. 103). Porém, esclarece que a absorção direta da dinâmica dessa sociedade não significa a eliminação do Eu, mas cria um obstáculo à sua capacidade de confrontar essa realidade e manter, assim, a busca pela autonomia e pela emancipação. Ao contrário, como sua força reside na heteronomia, o Eu que se forma pela conciliação com a realidade torna-se inabordável à experiência.?

Se, outrora, o conflito essencial entre a realização dos impulsos primários e a repressão imposta pela cultura possibilitava ao Eu se diferenciar e, também, se formar de modo (relativamente) autônomo, Marcuse (1967; 1998) observa que, nas sociedades administradas e tecnológicas, esse conflito se modificou e o resultado foi o afrouxamento na repressão aos impulsos sexuais, devido à realização cada vez mais ampliada dos desejos e das satisfações:

o conflito entre o princípio do prazer e o princípio de realidade é dirigido por meio de uma liberalização controlada, que realça a satisfação obtida com aquilo que a sociedade oferece. Mas nessa forma de liberação a energia libidinal muda sua função social: na medida em que a sexualidade é sancionada e até encorajada pela sociedade [...] ela perde a qualidade que, segundo Freud, é sua qualidade erótica essencial, a saber, o elemento de emancipação no que se refere ao social (MARCUSE, 1998, p. 106).

De início, poder-se-ia pensar que a satisfação e o prazer ampliados correspondem à liberdade na sociedade afluente, mas isto é falso porque, 
como ressalta o autor, não foi a liberdade individual que se ampliou, mas o controle social sobre o indivíduo. Esse processo revela

uma grande harmonia entre fora e dentro, pois a coordenação começa muito antes de tornar-se consciente: os indivíduos recebem de fora o que eles mesmos desejariam. A identificação com o ideal do ego coletivo ocorre na criança, ainda que a família já não seja o agente primário de socialização (MARCUSE, 1998, p. 100).

À fragilidade na constituição do Eu pode corresponder o aumento dos impulsos à agressão, os quais se dirigem indiscriminadamente para fora dos laços afetivos entre o indivíduo e suas relações imediatas. Como desdobramento, qualquer pessoa aparece como potencial inimigo se não for integrante do grupo ou, ainda, o inimigo é concreto, mas "também mais móvel e fungível, podendo encarar muitas formas conhecidas e odiadas, como os homossexuais, os estrangeiros, os intelectuais, os judeus, de acordo com o nível e o interesse do grupo social em questão" (MARCUSE, 1998, p. 104). À ilusão na qual os indivíduos se sentem livres pelo investimento de sua energia libidinal nos objetos fungíveis e obsoletos, o autor denomina como "dessublimação" que gera mais repressão. Para entender o aparente paradoxo desse processo, ressalta que

temos aqui um estágio de civilização altamente desenvolvido, em que a sociedade, ao ampliar a liberdade e a igualdade, subordina os indivíduos às suas exigências - em outros termos, em que o princípio de realidade se impõe por meio de uma dessublimação mais ampla, porém mais controlada. Sob essa forma histórica nova do princípio de realidade o progresso pode atuar como veículo da repressão (MARCUSE, 1998, p. 107).

Ao revelar os mecanismos de dominação que não podem ser apreendidos imediatamente, Marcuse aponta os aspectos subjetivos que resultam do conflito amortecido entre o Eu e a realidade: a satisfação com as mercadorias produzidas pelas sociedades administradas e tecnológicas intensifica a repressão e o controle social, que não necessitam mais de força bruta, bastando integrar o Eu fragilizado ao aparato social. Assim, ainda que os indivíduos se apropriem dos benefícios produzidos pela etapa tardia do capitalismo, eles "estão inextrincavelmente ligados às instâncias de produção e distribuição de bens de consumo, que crescem cada vez mais e ampliam sem cessar o aparato gigantesco, o qual precisa dessa expansão para defender tais instâncias dentro e fora das fronteiras nacionais" (MARCUSE, 1998, p. 107). Trata-se de uma situação engendrada por condições objetivas da vida social. Se o aparato produtivo, econômico e político-ideológico mobiliza 
todas as forças para promover a ilusão da liberdade, isso afasta a capacidade dos indivíduos de enfrentar as contradições inerentes à cultura e superá-las.

Mais que nunca, o grito de Adorno (1995) de que o único poder efetivo contra o "princípio de Auschwitz" é a autonomia e o seu poder para a reflexão, para a autodeterminação e para a não integração, revela-se absolutamente atual. Para o autor, a formação cultural do indivíduo é o caminho que pode levar as pessoas a se envergonharem de dar cotoveladas e de desejar a eliminação do outro. Em síntese, a luta contra a violência e a barbárie é a luta contra a deformação da individualidade, isto é, a constituição de um Eu frágil, imposta por processos objetivos nas sociedades administradas e tecnológicas em que vivemos.

(DE)FORMATION OF INDIVIDUALITY AND (IN)DISPOSITION TO THE VIOLENCE: SUBJECTIVE AND OBJECTIVE PRESUPPOSITIONS

ABSTRACT: The reflections developed here seek to analyze how the constitution of the "I" from the relationship between individual and culture, considering subjective and objective aspects, can result in renunciation or disposition to violent behavior. Through the assumptions of frankfurtian critical theory, especially in H. Marcuse, T. W. Adorno and M. Horkheimer, it is based on the Freudian analysis that recognizes the importance of the authority of the "father" within the nuclear family for the constitution of the "I", however, this discussion is updated and it is questioned whether the objective conditions of existence in the present era, in the era of administered and technological societies, would not beleading to the formation of a individuality available to join and practice violence.

KEYWORDS: Formation. Individuality. Violence. AdministeredandTechnologicalSociety.

(DE)FORMACIÓN DE LA INDIVIDUALIDAD E (IN)DISPOSICIÓN PARA LA VIOLENCIA: SUPUESTOS SUBJETIVOS Y OBJETIVOS

RESUMEN: Las reflexiones aquí desarrolladas buscan analizar la constitución del "Yo" a partir de la relación entre individuo y cultura, por lo tanto considerando aspectos subjetivos y objetivos, puede resultar en renuncia o disposición para el comportamiento violento. Por medio de supuestos de la Teoría crítica Frankfurt, especialmente en H. Marcuse, T. W. Adorno y M. Horkheimer, se parte del análisis 
freudiano sobre la importancia de la autoridad del "padre" en el seno de la familia nuclear para la constitución del "Yo". Sin embargo, se busca actualizar esa discusión e indagar si las condiciones objetivas de existencia en la actualidad, en la era de las sociedades administradas y tecnológicas, no estarían llevando a la (de)formación de una individualidad más disponible para adherirse y practicar violencia.

Palabras clave: Formación. Individualidad. Violencia. Sociedad Administrativa y Tecnológica.

\section{NOTAS:}

10 texto apresentado parte dos estudos realizados para fundamentação teórica e metodológica de pesquisa de doutorado que resultou na tese Sociedade, futebol, torcidas organizadas e educação: da violência explícita às contradições não evidentes, defendida no ano de 2014 no Programa de Pós-Graduação em Educação/UFG/Regional Goiânia.

2 Freud não diferencia cultura de civilização, mas usa-as em sentido amplo para se referir a "tudo aquilo em que a vida humana se elevou acima de sua condição animal e difere da vida dos animais". Essa elevação pode ser observada em dois aspectos: "por um lado, inclui todo conhecimento e capacidade que o homem adquiriu com o fim de controlar as forças da natureza e extrair a riqueza desta para a satisfação das necessidades humanas; por outro, inclui todos os regulamentos necessários para ajustar as relações dos homens uns com os outros e, especialmente, a distribuição da riqueza disponível" (FREUD, 1974a, p. 16).

3 Freud (2011) adverte que essa separação conceitual não ocorre em uma situação real. Na verdade, trata-se de forças e esferas que se influenciam mutuamente.

4 Para Freud (1974b, p. 101), "libido é a expressão extraída da teoria das emoções. Damos esse nome à energia, considerada como uma magnitude quantitativa (embora na realidade não seja presentemente mensurável), daqueles instintos que têm a ver com tudo o que pode ser abrangido sob a palavra 'amor'".

5 No debate sobre os motivos que levaram à barbárie de Auschwitz, Adorno (1995) não tem dúvidas de que a luta contra a violência e a barbárie deveria ter primazia no processo de formação humana.

6 Isto explica, por exemplo, o sentimento recorrente e generalizado de muitas pessoas de que nas sociedades de capitalismo desenvolvido não há mais oposição e que não existem alternativas a elas. Na década de 1960, Marcuse (1969) captou esse movimento de"fim da utopia"; e mais tarde, no contexto da queda do muro que separava o mundo ocidental em capitalista e socialista/comunista, esse movimento se renovou na tese do "fim da história". Como resposta a esse tipo de afirmação oportunista, Hobsbawm (1995, p. 18) esclarece que "o argumento é melhor quando se afirma que o terceiro 
quartel do século $[X X]$ assinalou o fim dos sete ou oito milênios de história humana iniciados com a revolução da agricultura na Idade da Pedra".

7 Ao se referir à personalidade das pessoas capazes de promover uma nova "Auschwitz", Adorno $(1995,1965)$ lembra que esta geralmente apresenta um "caráter manipulador" e uma "consciência coisificada" em que o resultado, no âmbito das relações sociais, é uma profunda incapacidade para a realização de "experiência" na perspectiva da autonomia e da liberdade.

\section{REFERÊNCIAS}

ADORNO, T. W. Educação e emancipação. Rio de Janeiro: Paz e Terra, 1995. .; FRENKEL-BRUNSWIK, E.; LEVINSON, D. J.; SANFORD, R. N. Introdução. In: La personalidad autoritaria. Buenos Aires: Editorial Proyección, 1965.

COSTA, J. F. Violência e psicanálise. Rio de Janeiro: Edições Graal, 2003.

FREUD, S. O futuro de uma ilusão. In: . Edição standard brasileira das obras completas de Sigmund Freud. Rio de Janeiro: Imago, 1974a. v. 21.

. O mal estar na civilização. São Paulo: Penguim Classics; Companhia das Letras, 2011.

. Psicologia de grupo e análise do ego. In: . Edição standard brasileira das obras completas de Sigmund Freud. Rio de Janeiro: Imago, 1974b. v. 18.

HOBSBAWM, E. J. Era dos extremos: o breve século XX. São Paulo: Companhia das Letras, 1995.

HORKHEIMER, M. Autoridade e família. In: Teoria crítica: uma documentação. São Paulo: Perspectiva, 1990.

;ADORNO, T. W. Temas básicos da sociologia. São Paulo: Cultrix, 1973.

MARCUSE, H. A ideologia da sociedade industrial. Rio de Janeiro: Zahar Editores, 1967. . A obsolescência da psicanálise. In: Cultura e sociedade. Rio de Janeiro: Paz e Terra, 1998. v. 2.

Algumas implicações da tecnologia moderna. In: . Tecnologia, guerrae fascismo. São Paulo: Fundação Editora da UNESP, 1999. . O fim da utopia. Rio de Janeiro: Paz e Terra, 1969.

ZANOLLA, S. R. S. Educação e barbárie: aspectos culturais da violência na perspectiva da teoria crítica da sociedade. Sociedade e cultura, Goiânia, v. 13, n. 1, p. 117-123, jan./ jun. 2010. 
SOUZA, L.C.

Luís CésAR SOUZA: Doutor em Educação. Docente no programa de pós-graduação em Educação da Universidade Federal de Goiás/Regional Jataí. Docente no curso de graduação em Educação Física - licenciatura e bacharelado.

E-mail: lucceso@hotmail.com 